Original scientific paper

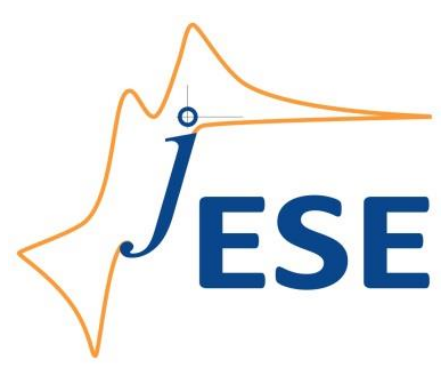

Open Access : : ISSN 1847-9286

www.jESE-online.org

\title{
Electrochromism in tungsten oxide thin films prepared by chemical bath deposition
}

\author{
Julijana Velevska ${ }^{1, \bowtie}$, Nace Stojanov ${ }^{1}$, Margareta Pecovska-Gjorgjevich ${ }^{1}$, \\ Metodija Najdoski² \\ ${ }^{1}$ Institute of Physics, Faculty of Natural Sciences and Mathematics, University Sts Cyril and \\ Methodius, Arhimedova 3, 1000 Skopje, Republic of Macedonia \\ ${ }^{2}$ Institute of Chemistry, Faculty of Natural Sciences and Mathematics, University Sts Cyril and \\ Methodius, Arhimedova 5, 1000 Skopje, Republic of Macedonia
}

${ }^{\otimes}$ Corresponding author: julev@pmf.ukim.mk;Tel.: +389 23249860

Received: November14, 2016; Revised: February14, 2017; Accepted: February 15, 2017

\begin{abstract}
Tungsten oxide $\left(\mathrm{WO}_{3}\right)$ thin films were prepared by a simple, economical, chemical bath deposition method onto fluorine doped tin oxide (FTO) coated glass substrates. The electrochemical properties of the films were characterized by cyclic voltammetry. The obtained films exhibited electrochromism, changing color from initially colorless to deep blue, and back to colorless. Visible transmittance spectra of $\left(\mathrm{WO}_{3}\right)$ films were recorded insitu in their both, bleached and colored states. From those spectra, absorption coefficient $(\alpha)$ and the optical energy gaps were evaluated. The dependence of the optical density on the charge density was examined and the coloration efficiency ( $\eta$ ) was calculated to be $22.11 \mathrm{~cm}^{2} \mathrm{C}^{-1}$. The response times of the coloring and bleaching to an abrupt potential change from $-2.5 \mathrm{~V}$ to $+2.5 \mathrm{~V}$ and reverse, were found to be 9.3 and $1.2 \mathrm{~s}$ respectively. The maximum light intensity modulation ability of the films, when the AM1.5 spectrum is taken as an input, was calculated to be about $50 \%$.
\end{abstract}

\section{Keywords}

Optical materials; cyclic voltammetry; response time; solar light modulation

\section{Introduction}

Electrochromism is a unique property of the material to change reversibly its optical properties when it is electrochemically reduced or oxidized [1]. Electrochromic materials exhibit color change between the clear transparent state and a darkened colored state, or between two colored states. At the same time, there are materials that exhibit multiple colored states and are described as 
polyelectrochromic. The classification of the electrochromic materials is related to the potential at which the coloration process occurs. Materials with cathodic coloration exhibit coloration at negative potential, i.e. they darken upon reduction (charge insertion). Anodic materials, on the other hand, exhibit coloration at positive potential, i.e. they darken upon oxidation (charge extraction). When the electrochromic material is integrated in device, it could modulate the reflectance/transmittance of the incident illumination [2]. Electrochromic materials are currently attracting much interest in academia and industry for both their spectroelectrochemical and commercial applications [3]. Electrochromism is known to exist in many types of materials, both organic and inorganic. Common inorganic electrochromic materials are transition metal oxides and metal hexacyanometallates, while viologens, phthalocyanines, conducting polymers and metallopolymers are common organic and polymer electrochromic materials.

Transition metal oxides have attractive technological importance for electrochromic applications because they show considerable variation in stoichiometry, and can be quite easily deposited in a form of thin film which is appropriate for device manufacturing. Among them, tungsten oxide $\left(\mathrm{WO}_{3}\right)$ is of intense interest and has been extensively investigated due to its appreciable electrochromic properties in the visible and infrared region. It exhibits large optical modulation, good durability, low power consumption, less stress for the viewer's eyes, and relatively low price [4].

Eectrochromic $\mathrm{WO}_{3}$ thin films have been prepared by a large number of techniques, such as thermal evaporation, electrodeposition, spray pyrolysis, chemical vapor deposition, electron beam evaporation, magnetron sputtering, sol-gel methods [5 - 16] etc. Among these techniques, chemical bath deposition methods have many advantages: they do not require sophisticated expensive equipment, various substrates including metals, semiconductors or insulators can be used, the starting chemicals are commonly available and cheap, and the preparation parameters are easily controlled [17 - 21]. These methods have benefit of being easily realizable from the point of view of industrialization, especially on large area devices, with the required electrochromic properties $[22,23]$. The electrochromic properties of $\mathrm{WO}_{3}$ thin films, like the transmittance modulation $(\Delta T)$, coloration efficiency $(\eta)$, switching time $(\tau)$, and cyclic durability, strongly depends on their structural, morphological and compositional characteristics [1, 2], which, in turn, depends directly on the deposition method and deposition conditions.

The target of this research is to investigate electrochromic properties of $\mathrm{WO}_{3}$ thin films prepared by a simple chemical bath deposition method [24] and their possible application for solar light modulation.

\section{Experimental}

Tungsten oxide films were deposited onto fluorine doped tin oxide (FTO) coated glass substrates commercially available with transparency of about $80 \%$ for visible light, and sheet resistance of about $10-20 \Omega \square^{-1}$. Before the deposition, the substrates were immersed in acetone and ethanol to be degreased in an ultrasonic bath, and then rinsed in deionized water and dried in air. $\mathrm{WO}_{3}$ films were deposited from a chemical bath with optimized composition and process conditions.

The bath solution was prepared by dissolving $1.65 \mathrm{~g} \mathrm{Na}_{2} \mathrm{WO}_{4} \cdot 2 \mathrm{H}_{2} \mathrm{O}$ in $90 \mathrm{ml}$ deionized water. The substrates were immersed in the beaker filled with deposition solution, and vertically supported against its walls. Then, the whole system was heated slowly, up to $95^{\circ} \mathrm{C}$ with continuous stirring. The preparation of the bath solution and the deposition of the thin films have been explained in details in Ref. [24]. The thickness of the films depends on the deposition time. In this work the deposition time was $20 \mathrm{~min}$, and the thickness of the films was $150 \mathrm{~nm}$. 
The electrochemical properties of $\mathrm{WO}_{3}$ films were characterized by cyclic voltammetry measurements performed using Micro AUTOLAB II equipment (Eco-Chemie, Utrecht, Netherlands) in one compartment three electrodes electrochemical cell with $\mathrm{WO}_{3}$ film as working, platinum wire as counter, and saturated calomel electrode (SCE) as a reference electrode. The cycling was carried out in $1 \mathrm{moldm}^{-3} \mathrm{KCl}$ aqueous solution as an electrolyte. The voltage scan rate was $10 \mathrm{mV} \mathrm{s}^{-1}$, and the film working area was $1 \mathrm{~cm}^{2}$.

Electrochromic investigations were performed in situ in an electrochromic device (ECD) consisted of: home-built glass cell $(4 \times 2.5 \times 4 \mathrm{~cm}), \mathrm{WO}_{3}$ film deposited on FTO substrate as working electrode (WE), blank FTO substrate as counter electrode (CE), and $1 \mathrm{moldm}^{-3} \mathrm{KCl}$ aqueous solution as an electrolyte. The distance between the electrodes was about $1.5 \mathrm{~cm}$, the volume of the electrolyte was about $20 \mathrm{ml}$, and the active surface area of the electrodes was approximately $6 \mathrm{~cm}^{2}$.

The optical transmittance spectra were recorded by using Varian CARY 50 Scan UV-Visible spectrophotometer in the wavelength range from 300 to $900 \mathrm{~nm}$, in both, the completely colored and bleached states of the film. An electrochromic cell with two clean FTO substrates filled with electrolyte was measured as $100 \%$ background. Coloration and bleaching of the film were performed with $-2.5 \mathrm{~V}$ and $+2.5 \mathrm{~V}$ respectively. Spectra were recorded $3 \mathrm{~min}$ after the voltage was applied. In order to obtain intermediate states of coloration, the film was also colored with coloration potentials of $-1.5 \mathrm{~V}$ and $-2 \mathrm{~V}$.

The visible transmission spectra were used for evaluation of the optical band gaps $E_{\mathrm{g}}$ of the $\mathrm{WO}_{3}$. For that purpose, the absorption coefficient $(\alpha)$ was evaluated from the transmittance data $(T)$ and the film thickness $(t)$, using the equation [25]:

$$
\alpha=\frac{1}{t} \ln \frac{1}{T}
$$

The optical band gaps of the film were evaluated from the absorption coefficient by fitting the data to the relation [26 - 28]:

$$
\alpha h v=A\left(h v-E_{\mathrm{g}}\right)^{\mathrm{n}}
$$

where, $A$ is a constant, $h v$ is the energy of the incident photon, $E_{\mathrm{g}}$ is the optical energy gap, and $n$ is a number which determines the type of electron transition causing the absorption. The value of $n$ is $1 / 2$ for direct allowed, $3 / 2$ for direct forbidden, 2 for indirect allowed, and 3 for indirect forbidden transitions.

The coloration efficiency $(\eta)$ of the $\mathrm{WO}_{3}$ was calculated from the optical density change $(\triangle O D)$ at a wavelength of $700 \mathrm{~nm}$, and the charge density $(\Delta Q / S)$ during coloration after the films were fully bleached:

$$
\eta=\frac{S \log \left(T_{\mathrm{b}} / T_{\mathrm{c}}\right)}{\Delta Q}
$$

where $T_{\mathrm{b}}$ and $T_{\mathrm{c}}$ are the transmittance of the fully bleached and colored states respectively, $\Delta Q$ is the injected charge, determined by the applied current and the time of its application, and $S$ is the active area of the electrochromic film.

The time needed for the electrochromic film to reach some fraction (usually above $70 \%$ ) of its maximum colored or bleached state (response time, $\tau$ ) was examined as a change in the transmittance at $700 \mathrm{~nm}$ due to abrupt voltage change between $+2.5 \mathrm{~V}$ and $-2.5 \mathrm{~V}$.

For an electrochromic material to be practically successful, it must have the ability to switch between its bleached and colored states frequently, whilst maintaining other important features 
consistently. Cycle life is defined as the number of cycles completed before the material fails, and measures material stability. The cycling behavior of chemically deposited $\mathrm{WO}_{3}$ films during electrochromic switching was directly observed spectroscopically by the in situ measurements of the transmittance at $700 \mathrm{~nm}$ of the fully bleached and colored states of the film after some number of cycles. The cycling was performed by alternatively applying potential of $\pm 2.5 \mathrm{~V}$.

The ability to switch between two states (bleached and colored) in a relatively short response time makes the tungsten oxide films a possible candidate for transmittance modulation device. Taking the solar irradiance spectrum AM1.5 for a normal incident illumination on tungsten oxide based electrochromic device $\left(\mathrm{ECD}=\right.$ glass $/ \mathrm{FTO} / \mathrm{WO}_{3} /$ electrolyte/FTO/glass) and the absorption coefficient spectra of the $\mathrm{WO}_{3}$ film in its bleached and colored states, the output integral of the spectral intensity and the integral of the spectral modulation could be calculated [29].

\section{Results and discussion}

The $\mathrm{WO}_{3}$ films investigated in this work exhibited good electrochromic behavior. They could be repeatedly colored and bleached by alternative application of a negative and positive potential respectively, versus a counter electrode. $\mathrm{WO}_{3}$ is cathodically coloring material which means that it possesses a reduced colored state. It is transparent in oxidized state (positive potential), and has a deep blue color in reduced state (negative potential). The X-ray diffraction (XRD) analysis showed that the films were crystalline [24].

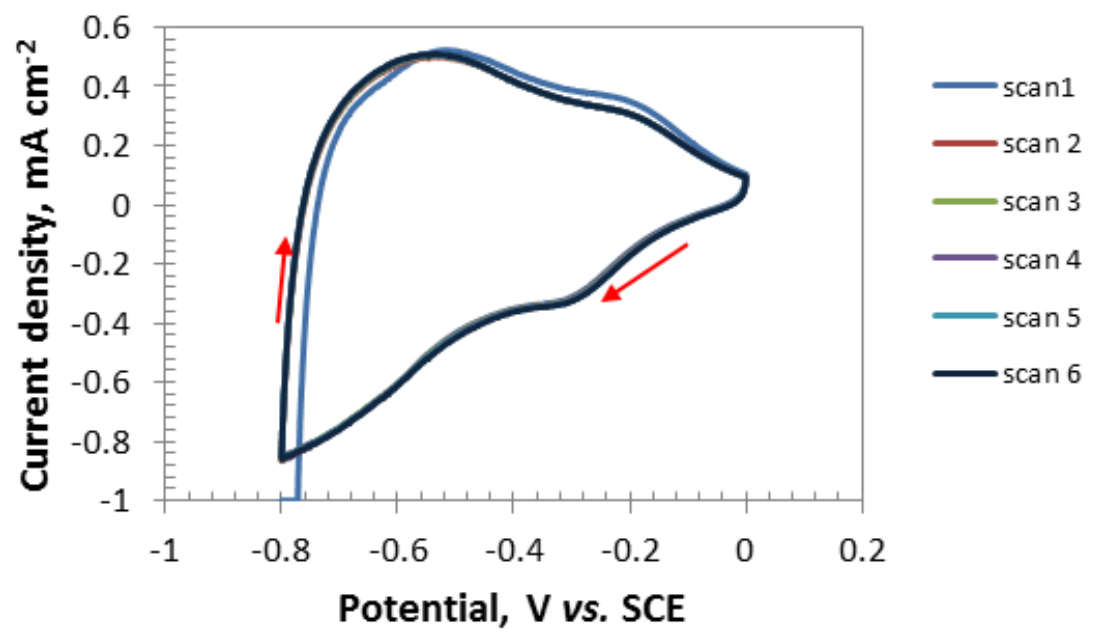

Figure 1. Cyclic voltammetric curves (six cycles) of chemically deposited $\mathrm{WO}_{3}$ thin film. Arrows indicate direction of the potential scan.

The electrochromic behavior of the films was examined by cycling voltammetry. The cyclic voltammetric (CV) curves were obtained by sweeping the potential in the range of $-0.8 \mathrm{~V}$ to $0 \mathrm{~V} v \mathrm{v}$. SCE at scanning rate of a $10 \mathrm{mV} \mathrm{s}^{-1}$. In Fig. 1 are presented six CV curves of the $\mathrm{WO}_{3}$ thin film. As can be seen all CV curves (except the first one) have a same shape, which means that the films exhibited good stability. The CV curves also showed an increase of the cathodic current density to $-0.86 \mathrm{~mA} \mathrm{~cm}^{-2}$ at $-0.8 \mathrm{~V}$, due to the reduction process occurring in the film and its switching to the blue color, whereas the anodic peak is observed at around $-0.541 \mathrm{~V}$ due to the oxidation process and bleaching of the film. The coloring process is followed by reduction of $\mathrm{W}^{\mathrm{Vl}}$ ions and double injection of potassium ions and electrons, and the bleaching process is followed by oxidation of $W^{V}$ ions and double extraction of potassium ions and electrons. The following equation can express the coloring/bleaching process: 


$$
\mathrm{WO}_{3} \text { (transparent) }+\mathrm{xK}^{+}+\mathrm{xe}^{-} \leftrightarrow \mathrm{K}_{\mathrm{x}} \mathrm{WO}_{3} \text { (blue) }
$$

It was observed [30] that during the coloration process, the XRD peaks change in the position and in the intensities indicating a structural transition associated with intercalation of ions. When the ions were deintercalated by applying reverse potential, the crystalline structure reverts to the initial lattice. However, this phenomenon remains to be studied in our future research.

The optical transmittance of the films was recorded to understand the type of electron transition and it was used to evaluate optical energy gap. By analyzing the optical transmission spectra, it is also possible to determine whether the optically induced transition is direct or indirect, and allowed or forbidden.

The optical transmission spectra of the $\mathrm{WO}_{3}$ film in the wavelength range from 350 to $900 \mathrm{~nm}$ in both, bleached and colored states, taken in situ, are presented in Fig. 2. One can see significant transmittance difference (more than 60\%) that occurs in the red region of the visible spectrum with tendency to continue in the near infrared (NIR) region.

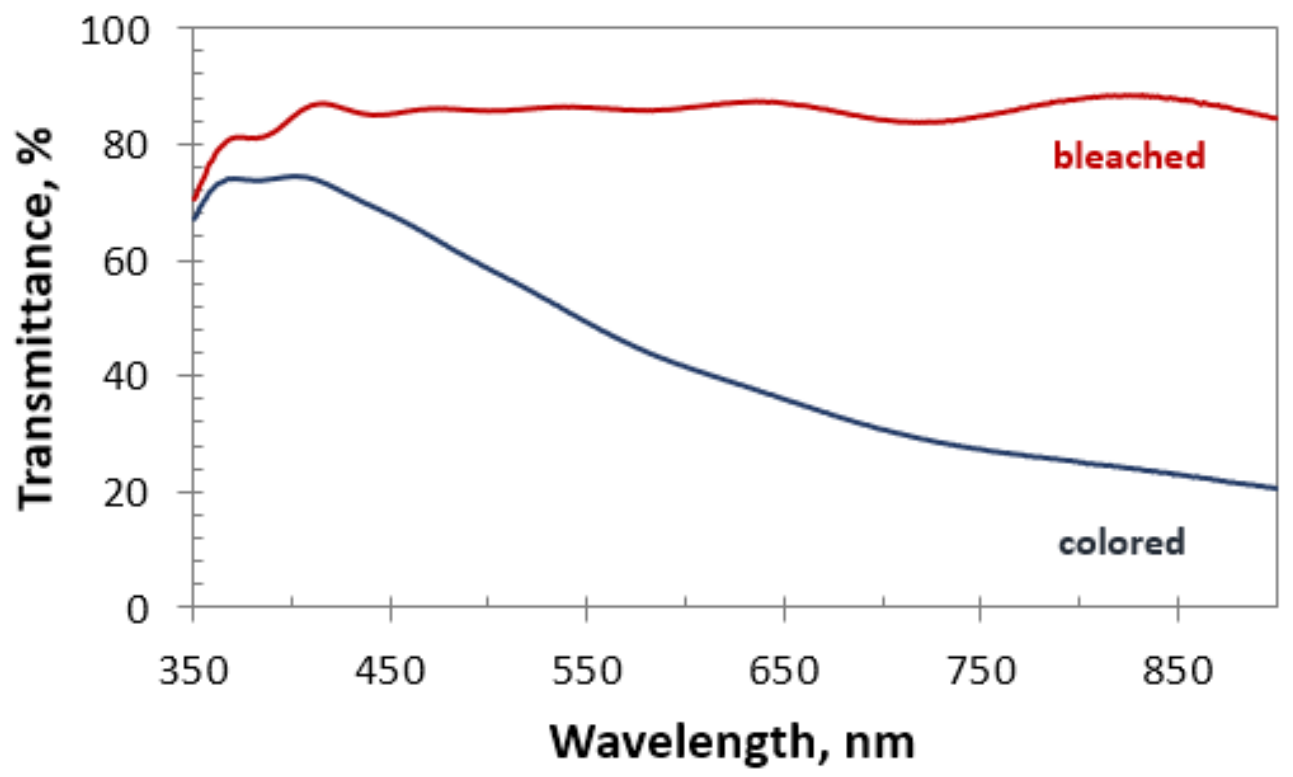

Figure 2. In-situ visible transmittance spectra of chemically deposited $\mathrm{WO}_{3}$ thin film in the bleached and colored states.

Fig. 3 shows the optical transmittance of the ECD constructed by using chemically deposited $\mathrm{WO}_{3}$ film in its bleached and colored states for an applied bleaching potential of $+2.5 \mathrm{~V}$ and coloring potentials of $-1.5 \mathrm{~V},-2 \mathrm{~V}$, and $-2.5 \mathrm{~V}$. The recorded transmission spectra for the device in the bleached state for positive potentials lower than $+2.5 \mathrm{~V}$ are indistinguishable from the spectrum of the device bleached at $+2.5 \mathrm{~V}$, and hence are not shown. Also, no difference was observed when negative potentials higher than $-1.5 \mathrm{~V}$ were applied. The film started to change its color at $-1.5 \mathrm{~V}$, and one can see that the spectra recorded at $-1.5 \mathrm{~V},-2 \mathrm{~V}$ and $-2.5 \mathrm{~V}$ are distinguishable from each other, and from the spectrum of the bleached state of the film. No significant difference was observed between the spectra recorded at coloration potentials of -2.5 and $-3 \mathrm{~V}$, which means that the film is wholly reduced at $-2.5 \mathrm{~V}$. Actual photographs of the device in the bleached $(+2.5 \mathrm{~V})$ and colored $(-1.5 \mathrm{~V},-2 \mathrm{~V}$, and $-2.5 \mathrm{~V})$ states are presented in Fig. 4. From these photographs one could clearly notice the different shades of blue obtained by different coloring potentials. 


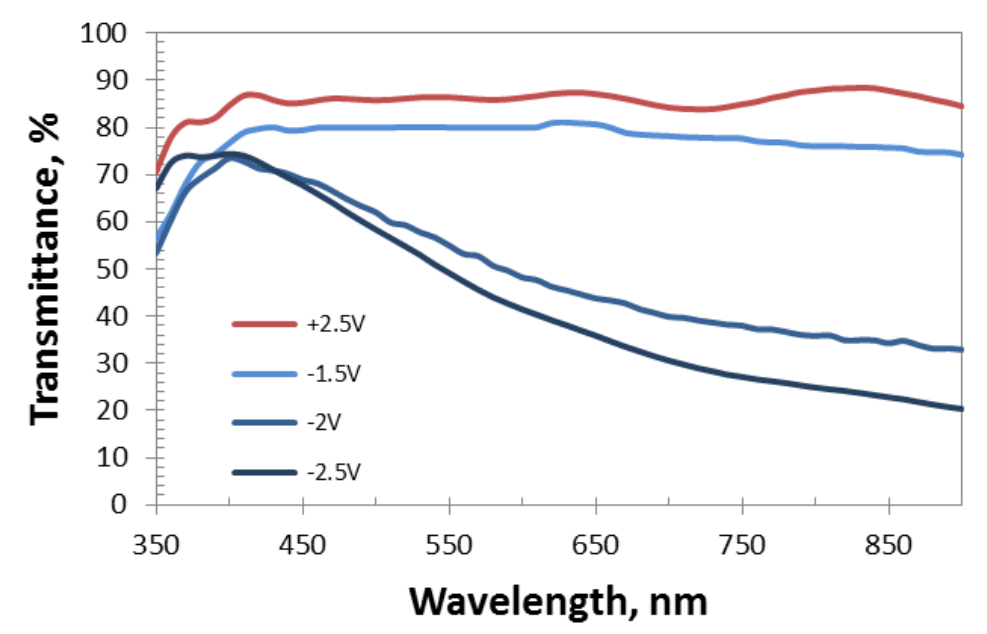

Figure 3. In-situ visible transmittance spectra of chemically deposited $\mathrm{WO}_{3}$ thin film bleached at $+2.5 \mathrm{~V}$ and colored $-1.5 \mathrm{~V},-2 \mathrm{~V}$, and $-2.5 \mathrm{~V}$.

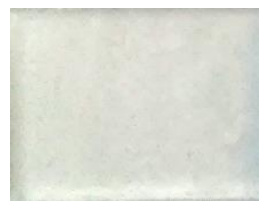

A

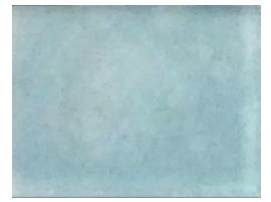

B

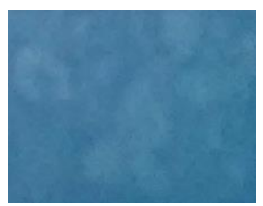

C

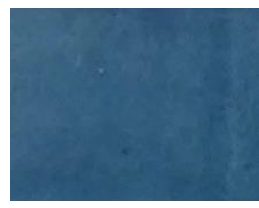

D

Figure 4. Photographs of ECD A: bleached at $+2.5 \mathrm{~V}$, B: colored at $-1.5 \mathrm{~V}, \mathrm{C}:-2 \mathrm{~V}$ and D:-2.5 V.

The optical energy gaps of the films were evaluated utilizing the transmittance data and the equations (1) and (2). The plots of $(\alpha h v)^{2}$ versus $h v$ for the chemically deposited $\mathrm{WO}_{3}$ thin film in both, bleached and colored states, are shown in Fig. 5 . The film showed a better fit for $n=0.5$ which shows the direct electron transition mechanism in both states (bleached and colored) of chemically deposited $\mathrm{WO}_{3}$ films. The energy gaps were calculated from the linear parts in Fig. 3 as intercepts with the photon energy axis. The evaluated band gaps for the film in its bleached and colored states were $3.38 \mathrm{eV}$ and $3.32 \mathrm{eV}$ respectively. These values are in good agreement with the reported values on tungsten oxide thin films [31].

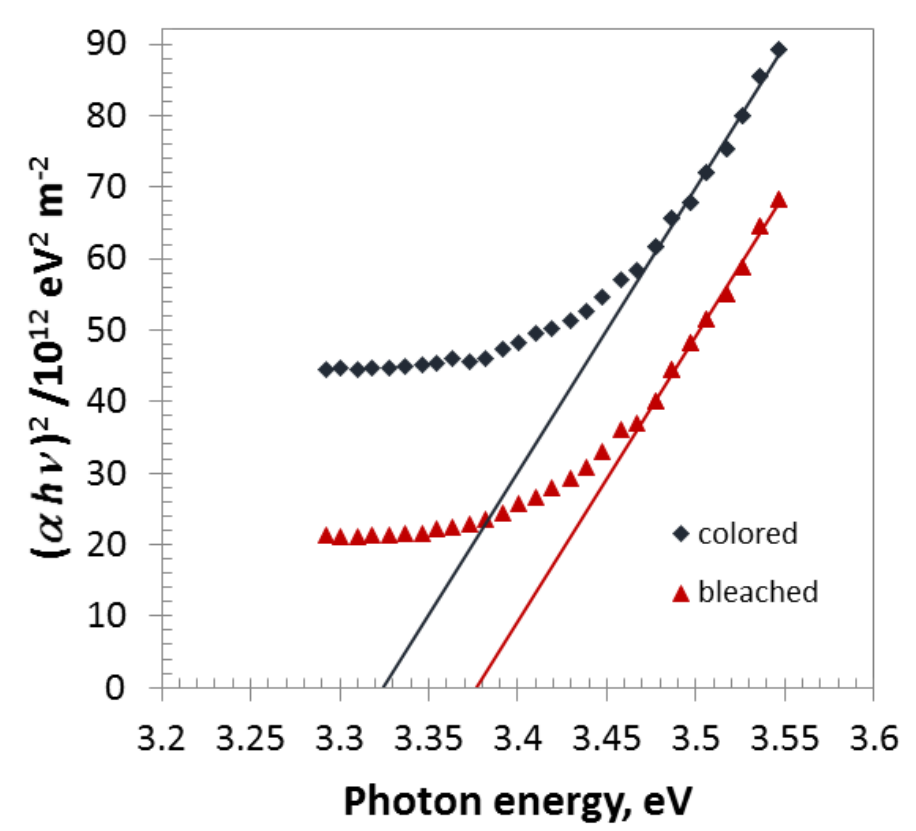

Figure 5. The plots of $(\alpha \mathrm{hv})^{2}$ vs. $\mathrm{h} v$ for $\mathrm{WO}_{3}$ thin films prepared by chemical bath deposition. 
To investigate in more detail the optoelectrochemical properties of the chemically deposited $W_{3}$ thin films, the optical density change $(\triangle O D)$ was plotted against the charge density change $(\Delta Q / S)$, and displayed in Fig. 6 . The coloration efficiency $\eta$ at $700 \mathrm{~nm}$ was extracted as the slope of the line fitted to the linear region of the curve. The calculated $\eta$ value was found to be $22.11 \mathrm{~cm}^{2} \mathrm{C}^{-1}$. The $\eta$ value obtained in this work is higher when compared to the values obtained for electrodeposited and sol-gel coated $\mathrm{WO}_{3}$ thin films [32-35], but lower compared to the values obtained for the sputtered $\mathrm{WO}_{3}[36]$.

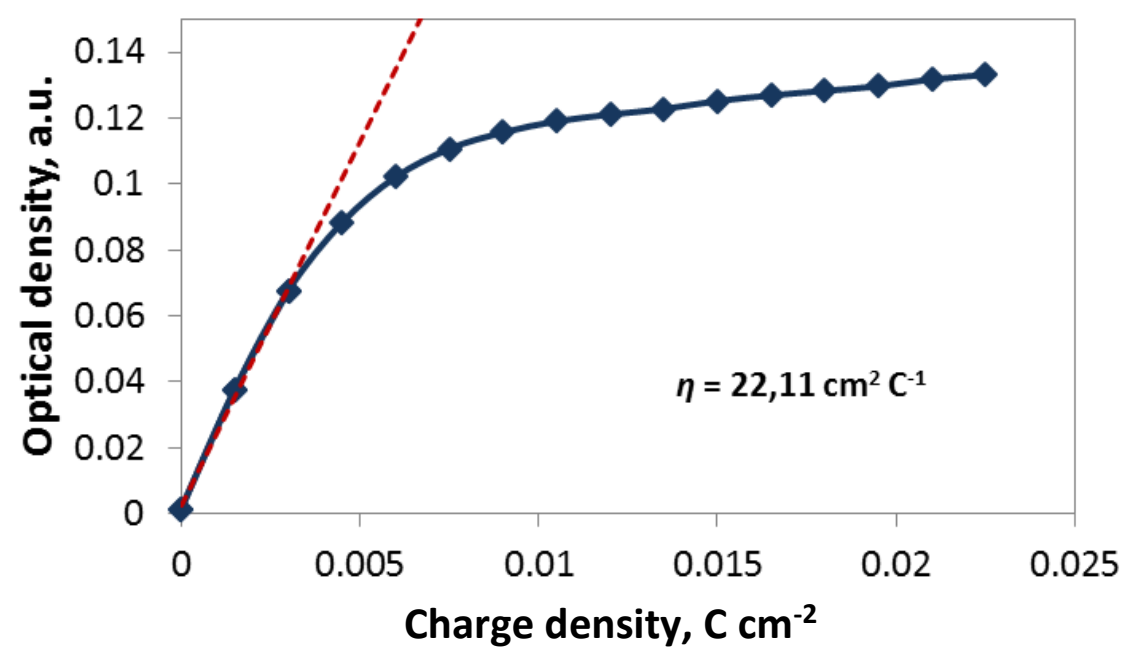

Figure 6. Optical density variationwith respect to the charge density measured at $700 \mathrm{~nm}$

In order to investigate the transition response time between coloration and bleaching, the transmittance was measured in-situ through the ECD. The applied potential was switched between $2.5 \mathrm{~V}$ (transparent state) and - $2.5 \mathrm{~V}$ (blue state). Fig. 7 shows the dynamic coloration/bleaching characteristics of the ECD, recorded at the wavelength of $700 \mathrm{~nm}$. The coloration and bleaching times $\left(\tau_{\mathrm{c}}\right.$ and $\tau_{\mathrm{b}}$ ), defined as time required for achieving $70 \%$ of the total transmission change $[37,38]$ was found to be $9.3 \mathrm{~s}$ and $1.2 \mathrm{~s}$ respectively, which means that the coloring kinetics is slower than the bleaching one. The faster bleaching time is due to the good conductivity of the tungsten bronze $\left(\mathrm{K}_{\mathrm{x}} \mathrm{WO}_{3}\right)$ and the conductor $\left(\mathrm{K}_{\mathrm{x}} \mathrm{WO}_{3}\right)$ to semiconductor $\left(\mathrm{WO}_{3}\right)$ transition. On the other hand, the slower coloration time is due to the higher resistance during $\mathrm{WO}_{3}$ to $\mathrm{K}_{\mathrm{x}} \mathrm{WO}_{3}$ transition [39].

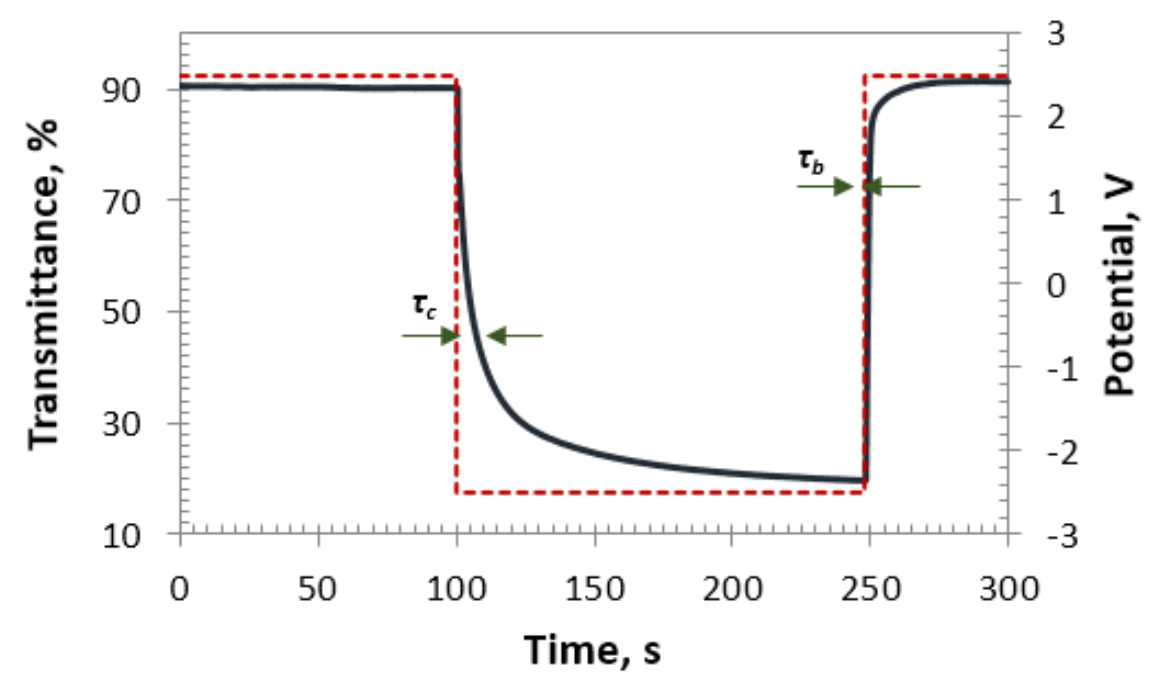

Figure 7. Switching time characteristics (at $700 \mathrm{~nm}$ ) between the colored and bleached states for ECD, measured at $\pm 2.5 \mathrm{~V}$. 
Fig. 8 shows the transmittance at $700 \mathrm{~nm}$ of the ECD in the bleached and colored states up to 10000 color-bleach cycles. As can be seen from Fig. 8, the transmittance shows insignificant variations which means that the electrochemically deposited $\mathrm{WO}_{3}$ films are stable and could be electrochemically switched for $10^{4}$ cycles without serious deterioration. Unfortunately, after the $10^{4}$ cycles the optical transmittance change rapidly decreased, so we could say that the device durability is up to $10^{4}$ cycles of bleaching and coloring.

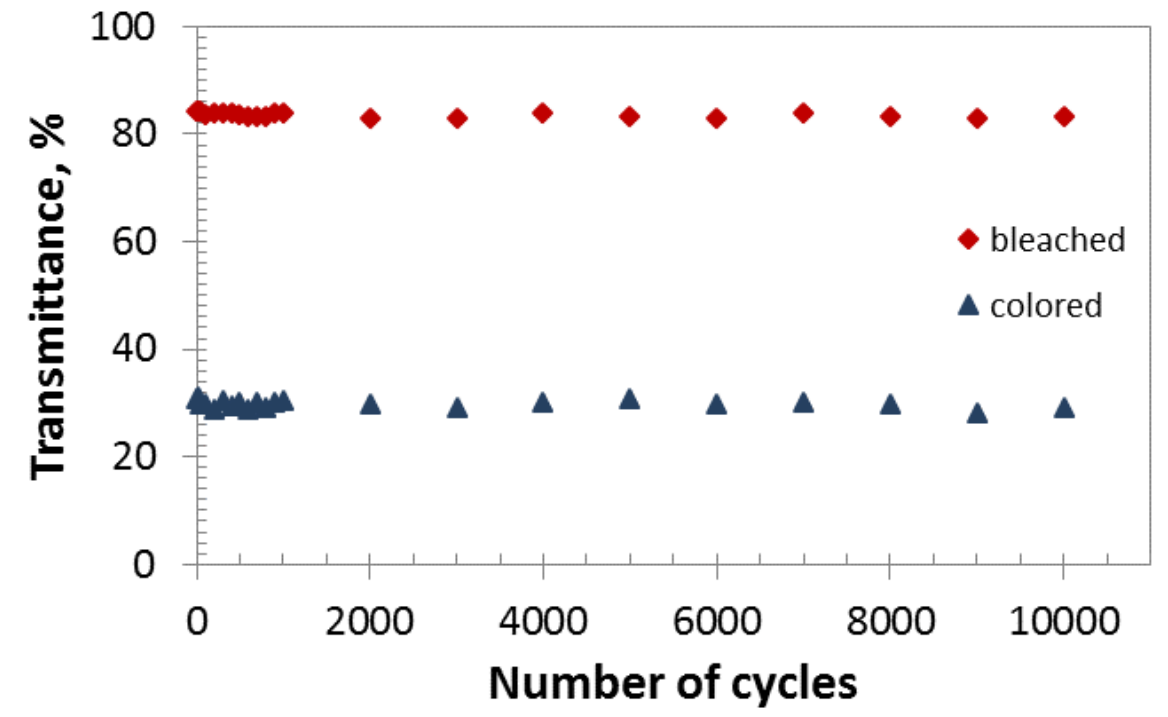

Figure 8. In-situ transmittance (at $700 \mathrm{~nm}$ ) of chemically deposited $\mathrm{WO}_{3}$ thin film in the bleached and colored states vs. number of cycles.

Finally, the irradiance of the solar spectrum AM 1.5 [40] and the absorption coefficient spectra (calculated from the transmittance spectra) of the chemically deposited $\mathrm{WO}_{3}$ films in their bleached and colored states (Fig. 9), were taken as input parameters. The output spectral intensities transmitted across the $\mathrm{WO}_{3}$ films were calculated and presented in Fig. 10. The results of the numerical integration for the spectral intensity within the visible region $(350-900 \mathrm{~nm})$ are presented in Table 1.

Table 1. Integral transmitted intensity from 350 to $900 \mathrm{~nm}\left(\mathrm{l}_{t}\right)$ through the $\mathrm{WO}_{3}$ films in their bleached and colored states.

\begin{tabular}{lc}
\hline \multicolumn{1}{c}{ State } & $\mathrm{I}_{\mathrm{t}} / \mathrm{W} \mathrm{m}^{-2}$ \\
\hline Bleached & 506 \\
Colored & 253 \\
\hline
\end{tabular}

The relative change of the integrated intensity (the visible transmitted intensity and the light modulation) could be calculated by the equation:

$$
\text { Modulation } \approx \frac{I_{\mathrm{t}}(\text { bleached })-I_{\mathrm{t}}(\text { colored })}{l_{\mathrm{t}}(\text { bleached })}
$$

Using the results from the Table 1 and the equation (5), the integrated intensity modulation of about $50 \%$ was achieved, which is considerable value that gives the opportunity for implementation of the chemically deposited $\mathrm{WO}_{3}$ films in electrochromic devices such as electrochromic windows. 


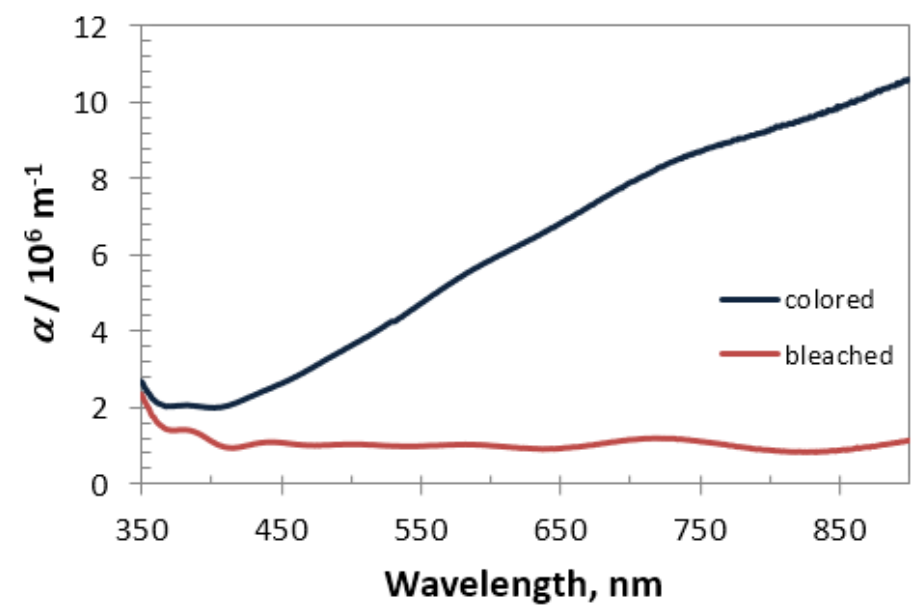

Figure 9. Absorption coefficient spectra of the chemically deposited $\mathrm{WO}_{3}$ film in the bleached and colored states.

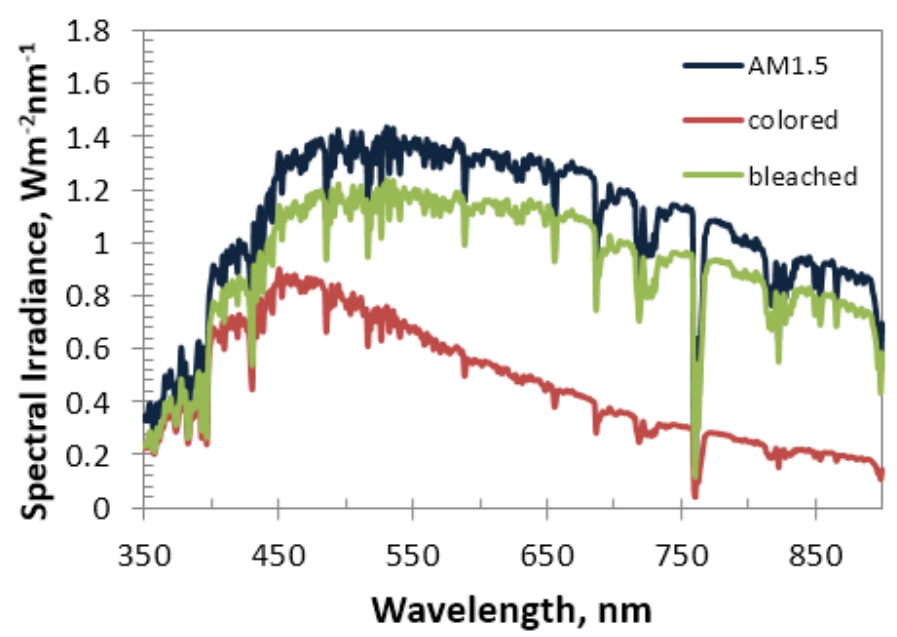

Figure 10. Spectral intensity of the transmitted AM 1.5 solar irradiance spectrum through the $\mathrm{WO}_{3}$ film in bleached and colored states

\section{Conclusions}

Tungsten oxide thin films investigated in this work were deposited onto FTO coated glass substrates by chemical bath deposition method. The method is simple, economical, and has benefit of being easily realizable from the point of view of industrialization, especially on large area devices, with the required electrochromic properties. The obtained films exhibited good electrochromic properties. They were stable and exhibited excellent reversibility, with color changed from originally colorless into deep blue when negative potential was applied, and back to colorless when the potential was reversed. Transmittance difference of more than $60 \%$ was achieved in the red region of the visible spectrum. Also, by controlling the coloring potential, intermediate states of coloration were achieved. Optical energy gaps were evaluated from the transmittance measurements for the both, bleached and colored states of the films, assuming a direct semiconductor transition mechanism. The coloration efficiency (at $700 \mathrm{~nm}$ ) was found to be $22.11 \mathrm{~cm}^{2} \mathrm{C}^{-1}$, the value higher compared with those obtained for electrodeposited and sol-gel coated $\mathrm{WO}_{3}$ thin films, but lower compared to the values obtained for sputtered $\mathrm{WO}_{3}$ thin films. The switching times between transparent and blue states of the $\mathrm{WO}_{3}$ thin film were found to be $9.3 \mathrm{~s}$ for coloring, and 1.2 for bleaching. The maximum light intensity modulation ability of the films, as the AM 1.5 spectrum is taken for an input, was calculated to be about $50 \%$ which is considerable value which makes chemically deposited tungsten oxide thin films suitable for application in electrochromic devices. 


\section{References}

[1] K. Bange, Solar Energy Materials \& Solar Cells, 58 (1999) 1-131

[2] C.G. Granqvist, Handbook of Inorganic Electrochromic Materials, Elsevier, Amsterdam, Holland, 1995, p.

[3] D.R. Rosseinsky, R.J. Mortimer, Acvanced Materials13(11) (2001) 783-793

[4] E. S. Lee, D. L. Di Bartolomeo,Solar Energy Materials \& Solar Cells, 71(4)(2002)465-491

[5] C. G. Granqvist, Solar Energy Materials \& Solar Cells, 60(2000)201-262

[6] M. C. Rao, O. M. Hussain, Research Journal of Chemical Sciences1 (7) (2011) 92-95

[7] P. M. S. Monk, Critical Reviews in Solid State and Materials Sciences 24 (1999) 193-226

[8] A. J. More, R. S. Patil, D. S. Dalavi, S. S. Mali, M. G. Gang, J. H. Kim, Materials Letters134 (2014) 298-301

[9] C. Y. Kim, S. G. Cho, S. Park, D. K. Choi, Journal of Ceramic Processing Research10 (6) (2009) 851-854

[10] A. A. Joraid, Current Applied Physics 9 (2009) 73-79

[11] R. U. Kirss, L. Meda, Applied Organometric Chemistry 12 (1998) 155 - 160

[12] D. Gogova, K. Gesheva, A. Szekeres, M. Sendova-Vassileva, physica status solidi (a)176 (1999) 969-984

[13] C. M. Wang, C. Y. Wen, Y. C. Chen, K. S. Kao, D. L. Cheng, C. H. Peng, Integrated Ferroelectrics: An International Journal158 (1) (2014)62-68

[14] T. S. Yang, Z. R. Lin, M. S. Wong, Applied Surface Science252 (2) (2005) 2029-2937

[15] F. Zhang, H. Q. Wang, S. Wang, J. Y. Wang, Z. C. Zhong, Y. Jin, Chinese Physics B23 (9) (2014) 098105(1-6)

[16] A. P. Baker, S. N. B. Hodgson, M. J. Edilisinghe, Surface and Coatings Technology153 (2) (2002) 184-193

[17] M. Ristova, J. Velevska, M. Ristov, Solar Energy Materials \& Solar Cells 71 (2002) 219-230

[18] T. Todorovski, M. Najdoski, J. Velevska, International Journal of Pure and Applied Chemistry1(4) (2006) 549-552

[19] R. Neskovska, M. Ristova, J. Velevska, M. Ristov, Thin Solid Films515 (2007) 4717-4721

[20] S. Demiri, M. Najdoski, J. Velevska, Material Research Bulletin46 (2011) 2484-2488

[21] J. Velevska, M. Pecovska-Gjorgjevich, M. Najdoski, N. Stojanov, Silpacorn University Science and Technology Journal5 (1) (2011) 34-42

[22] R. S. Mane, C. D. Lokhande, Materials Chemistry and Physics65 (2000) 1-31

[23] J. Cheng, D. B. Fan, H. Wang, B. W. Liu, Y. C. Zhang, H. Yan, Semiconductor Science and Technology, 18 (2003) 676-679

[24] M. Najdoski, T. Todorovski, Materials Chemistry and Physics104 (2007) 483-487

[25] J. M. O-Rueda de Leon, D. R. Acosta, U. Pal, L. Castaneda, Electrochimica Acta56 (2011) 2599-2605

[26] R. Bhat, I. Bhaumic, S. Ganesamoorthy, A. K. Karnal, M. K. Swami, H. S. Patel, P. K. Gupta, Physica Status Solidi A 209 (1) (2012) 176-180

[27] F. I. Ezema, A. B. C. Eqwealor, R. U. Osuji, Superficies Vacio21 (2008) 6-10

[28] A. Tumuluri, K. Lakshun Naidu, K. C. James Raju, International Journal of ChemTech Research6 (6) (2014) 3353-3356

[29] M. Ristova, R. Neskovska, V. Mircevski, Solar Energy Materials \& Solar Cells91 (2007) 13611365

[30] Y. Djaoued, S. Balaji, R. Brüning, Journal of Nanomaterials, 2012 (2012) Article ID 674168, 9 pages

[31] K. Srinivasa Rao, B. RajiniKanth, G. Srujana Devi, P.K. Mukhopadhyay, Journal of Materials Science-Materials in Electronics22 (2011) 1466-1472 
[32] J. R. De Andrarde, I. Cesarino, R. Zhang, J. Kanicki, A. Pawlicka, Molecular Crystals and Liquid Crystals604 (2014) 71-83

[33] M. Deepa, M. Kar, S. A. Agnihotry, Thin Solid Films, 468 (2004) 32-42

[34] C. G. Kuo, C. Y. Chou, Y. C. Tung, J. H. Chen, Journal of Marine Science and Technology20 (4) (2012) 365-368

[35] C. Y. Kim, S. Park, Asian Journal of Chemistry25 (10) (2013) 5874-5878

[36] S. H. Lee, H. M. Cheong, C. E. Tracy, A. Mascarenhas, A. W. Czanderna, S. K. Deb, Applied Physics Letters75 (11) (1999) 1541-1543

[37] J. Velevska, M. Pecovska-Gjorgjevich, N. Stojanov, M. Najdoski, International Journal of Sciences: Basic and Applied Research25 (3) (2016) 380-392

[38] Z. Jiao, X. W. Sun, J. Wang, L. Ke, H. V. Demir, Journal of Physics D: Applied Physics 43 (2010) 285501 (6pp)

[39] Z. Jiao, J. Wang, L. Ke, X. Liu, H. V. Demir, M. F. Yang, X. W. Sun, Electrochimica Acta 63 (2012) 153-160

[40] ASTM GI73-03 Standard Tables for Reference Solar Irradiances: Direct Normal and Hemispherical on $37^{0}$ Tilted Surface (2012)

(C)2017 by the authors; licensee IAPC, Zagreb, Croatia. This article is an open-access article distributed under the terms and conditions of the Creative Commons Attribution license (http://creativecommons.org/licenses/by/4.0/) 